\title{
Um estudo da função de operadores argumentativos usados no gênero editorial enquanto recursos na construção do discurso persuasivo
}

\author{
A study about argumentative operators' function used in \\ the editorial gender while resource in the construction of \\ the persuasive speech
}

Míriam Silveira Parreira*

\begin{abstract}
RESUMO: A proposta deste trabalho é analisar o uso de operadores argumentativos na construção de enunciados de editoriais, apresentando-os como correspondentes aos lugares da retórica clássica. Para tanto, objetivamos verificar de que forma eles podem funcionar enquanto recurso na construção do discurso persuasivo. O corpus que compõe esta pesquisa, de natureza qualitativa, compreende 03 editoriais extraídos de três jornais: Folha de S. Paulo, Estado de Minas e O Globo. Para a análise, tomamos como base os estudos de Koch (1984), ao abordar que pela linguagem, no processo de interação, procura-se a adesão do interlocutor, bem como na afirmação da autora de que há na língua mecanismos que podem ser usados na estruturação do texto para direcionar a argumentação. Usamos como base teórica os estudos de Perelman e Olbrecths-Tyteca (1999) que afirmam ser o discurso argumentativo escrito produzido com a finalidade de se obter a adesão de um interlocutor. As considerações feitas tendem a mostrar que o uso de operadores argumentativos pode tornar mais forte a argumentação dos editoriais de jornal, contribuindo para a persuasão.
\end{abstract}

PALAVRAS-CHAVE: Operadores argumentativos. Editorial de jornal. argumentação.

ABSTRACT: The purpose of this study is to analyze the use of argumentative operators in the constructions of statements in newspaper editorials, presenting them as correspondents to the classical rhetoric. In order to do such, we aimed verify how they can function as a resource in the construction of the persuasive discourse. The corpus of this research, of qualitative and quantitative nature, is made up of 03 editorials from three newspapers: O Globo, Folha de São Paulo and Estado de Minas. The analysis is based in studies of Koch (1984) were also used when she states that, in the interaction process through language, the adhesion of the interlocutor is sought for; she also states that, there are mechanisms in the language, which can be used in the structuring of the text, in order to direct the argumentation. We used as a

* Doutoranda em Estudos Linguísticos do Instituto de Letras e Linguística da Universidade Federal de Uberlândia (UFU), mestre em Linguística pela Universidade Federal de Uberlândia (UFU), especialista em Literatura Brasileira pela Pontifícia Universidade Católica de Minas Gerais. E-mail: miriamsparreira@uol.com.br. 
complementary basis the studies of Perelman \& Olbrecths-Tyteca (1999), which state that the written argumentative discourse is produced with the intention of obtaining adhesion of an interlocutor.

KEYWORDS: Argumentative operators. Newspaper editorial. Argumentation.

\section{Introdução}

Quando lemos o jornal, tendemos, até por uma questão de boa fé quase que instintiva, a acreditar na palavra escrita. Entretanto, o que se apresenta escrito é uma espécie de construção, de representação da realidade porque passou por um deslocamento, por uma transformação que pode alterar o significado real do acontecimento. Analisando dessa forma, podemos dizer que, embora se proponha a falar da realidade, de se reportar ao real, o jornalista necessariamente recorta fragmentos da realidade e a transfere para o universo do próprio jornal, que é a representação diária do que está se passando no mundo. Assim, o jornalista se torna intérprete da realidade, tomando o lugar de enunciador que interpreta a sociedade.

Dessa forma, o sujeito (o jornalista) pretende ganhar a adesão dos outros sujeitos (os leitores) mediante a ideia que evidencia, já que o discurso jornalístico acaba precisando e dependendo da aceitação, muito mais do que qualquer obra, para poder sobreviver.

O editorial de jornal é uma categoria de texto que procura evidenciar as tendências ideológicas do jornal sobre temas polêmicos ou fatos surpreendentes. Muitos leitores o consideram como uma verdade porque ele tem o peso da palavra escrita, impressa, que "parece" uma forma acabada da verdade. Entretanto, o que pode escapar ao leitor é que essa escrita é uma ilusão construída no universo do jornal, na tentativa de interpretar fatos da realidade.

Por esse motivo, não há dúvidas de que o editorial de jornal merece nossa atenção, porque trata de temas variados e polêmicos e traz, diariamente, a sua versão da realidade e nem sempre tomamos consciência disso. Segundo 
Agustini (informação verbal ${ }^{1}$ ), o bom editorial é aquele que apaga a presença do enunciador e coloca o argumento como sendo objetivo, dando logicidade para o que está sendo produzido. Ele, a princípio, deveria apresentar apenas a opinião do jornal, mas vai além do seu propósito porque se utiliza de recursos argumentativos que criam, segundo Agustini (2006) um efeito de implicação, valendo-se do senso comum para fazer "parecer" que a conclusão lógica, possível é a defendida por ele.

Dessa forma, o editorial, que deveria ser um texto apenas opinativo, passa a caracterizar-se pela persuasão. Isto é, chega a distorcer a característica básica de apresentar sua opinião sobre o assunto, passando, na verdade, à explícita tentativa de convencer o leitor e conduzi-lo a uma ação determinada pelo enunciador. Assim, por seu caráter argumentativo e pela necessidade de expressar a opinião do jornal, apoia-se em valores aceitos pelo senso comum e pode funcionar como formador de opinião.

Nesse sentido, Perelman e Olbrecths-Tyteca (1999) afirmam que são as relações que a argumentação possui com a ação é que comprometem praticamente os que dela participam. De acordo com a afirmação, salientamos que estamos considerando que o uso dos operadores argumentativos nos editoriais é uma das estratégias usadas para reforçar a argumentação, mas sabemos que existem outras, como por exemplo as escolhas lexicais, que podem contribuir também para a persuasão, mas não são objeto de nossa pesquisa.

O valor retórico - ou argumentativo - que se manifesta por meio de uma relação precisa entre enunciados, a de ser argumento para, segundo Koch (1984), é marcado por morfemas que funcionam como operadores argumentativos e discursivos. Koch (1984) identifica especialmente formas linguísticas de natureza argumentativa, inscritas nos textos, como marcadores explícitos de uma intenção. Dentre elas estão os operadores argumentativos,

\footnotetext{
${ }^{1}$ Consideração tecida pela Profa Drạ Carmen Lúcia Hernandes Agustini, durante o exame de qualificação da dissertação "Um estudo do uso de operadores argumentativos no gênero editorial de jornal", realizado na Universidade Federal de Uberlândia (UFU).
} 
marcas responsáveis pelo encadeamento dos enunciados, estruturadoras dos textos e determinantes de sua orientação argumentativa. Portanto, formas consideradas estratégias dos enunciadores para conduzirem a uma conclusão.

Em vista disso, dentro do quadro da Linguística Textual, formulamos a pergunta básica deste estudo: $O$ uso de certos operadores argumentativos que aparecem frequentemente no gênero editorial de jornal pode tornar a argumentação mais persuasiva? Nesse sentido, a questão levantada levou-nos a refletir sobre o modo como os argumentos são apresentados no gênero textual editorial de jornal, objeto de estudo desta pesquisa.

Em função dessa proposta, objetivamos analisar de que forma o uso de operadores argumentativos no gênero editorial pode funcionar enquanto recurso na construção do discurso persuasivo. Para a análise, recorte de nossa dissertação de mestrado, selecionamos, por motivo de espaço, apenas 03 (três) editoriais de três jornais diferentes: O Globo, Folha de São Paulo e Estado de Minas.

\section{Justificativa}

As questões levantadas nesta pesquisa resultam da leitura de editoriais de jornal e da observação de operadores argumentativos usados com frequência nesse gênero textual. A investigação desenvolvida nesta pesquisa justifica-se por haver nos editoriais marcas linguísticas de manobras discursivas adotadas pelos seus autores com uma intenção no âmbito do jornal e no âmbito social. Sendo assim, pode-se conscientizar o leitor do editorial a respeito da intenção argumentativa dessas marcas linguísticas, para percebê-las no discurso lido e até usá-las em seu próprio discurso, de modo eficaz. O estudo pode ser relevante se feito na sala de aula, a fim de tornar o aluno um leitor que reconhece técnicas argumentativas persuasivas e prepará-lo não só para ler como também para produzir textos argumentativos em que possa fazer uso de operadores argumentativos com uma intenção. 
A proposta de estudo que fazemos é resultado de uma preocupação com a necessidade de verificar como o uso dos operadores argumentativos no editorial contribui para que o editorialista exponha fatos que possam levar 0 leitor a assumir o seu ponto de vista. Além disso, levar o leitor a refutar conceitos pré-estabelecidos, conduzindo-o a uma conclusão desejada por quem escreve, o produtor do texto.

Assim sendo, acreditamos que nosso estudo possa ampliar as informações já existentes sobre os editoriais e a argumentação contribuindo, inclusive, para o desenvolvimento das habilidades de leitura e de escrita, pelo melhor conhecimento de como essa categoria de texto se constitui e funciona. Por esse motivo, nossos objetivos são: a) verificar o uso de operadores argumentativos usados nos editoriais de jornal; b) ajudar a esclarecer como o uso de operadores argumentativos nos editoriais de jornal objetiva chamar a atenção do leitor e induzi-lo à ação, que pode ou não levar à adesão da tese defendida.

Nesta pesquisa, hipotetizamos que: a) o uso de certos operadores argumentativos que aparecem no gênero editorial pode determinar a orientação argumentativa dos enunciados pertencentes ao corpus deste estudo; b) a linguagem dos editoriais de jornal tem características próprias que objetivam chamar a atenção do leitor e induzi-lo à ação que pode ou não levar à adesão da tese defendida.

\section{Material e métodos}

O corpus desta análise, recorte de nossa dissertação de mestrado, é constituído de 03 (três) editoriais de jornal veiculados em três jornais: $O$ Globo, Folha de S.Paulo e $O$ Estado de Minas. O levantamento do corpus considerou editoriais publicados no período compreendido entre os meses de julho de 2004 até novembro de 2004.

A opção feita por catalogar os editoriais de jornais de circulação nacional justifica-se: a) pelo conceito que possuem diante dos brasileiros que têm 
acesso a eles; b) por serem veículos de comunicação nacional; c) por direcionarem suas informações a um público que se interessa por assuntos atuais e diversificados.

Não objetivamos comparar a linguagem argumentativa utilizada por um ou outro jornal, mas explicitar os valores dos operadores argumentativos presentes no discurso persuasivo e analisar como se processa a argumentação no gênero textual selecionado. Foi esse o motivo que nos levou a optar pela análise de editoriais jornalísticos de mais de um jornal. Ademais, dessa maneira não correremos o risco de analisar textos escritos com apenas um estilo, evitando-se na verificação de regularidades a interferência do viés de um grupo único de produtores.

Para atingir nossos objetivos, nossa pesquisa está dividida em três partes. Na primeira parte, fizemos uma revisão bibliográfica para examinar questões relativas ao uso dos operadores argumentativos, ao gênero textual editorial e a técnicas argumentativas, tratados por autores que julgamos expressivos e para estabelecer nosso ponto de vista teórico acerca do assunto.

$\mathrm{Na}$ segunda parte, fizemos um levantamento das técnicas argumentativas mais usadas no processo de argumentação do gênero editorial, adotadas como ponto de partida para o processo de comunicação.

$\mathrm{Na}$ terceira parte, procuramos verificar os efeitos de sentido que o uso de certos operadores argumentativos pode causar no leitor do editorial de jornal e demonstrar, por meio de exemplos do corpus, que a linguagem dos editoriais tem características próprias que objetivam chamar a atenção do leitor e induzi-lo à ação que pode ou não levar à adesão.

Finalmente, concluímos a pesquisa procurando sintetizar as constatações mais significativas e estabelecer considerações com base na análise feita. Nesse sentido, procuramos evidenciar que os editoriais de jornal têm mecanismos acionados, de maneira consciente ou não, pelos produtores do texto para elaborar ideias, rechaçar preconceitos e assumir pontos de vista acerca dos fatos abordados. 
Não pretendemos apresentar uma análise exaustiva pelas limitações próprias de qualquer análise. Entretanto, esperamos apresentar resultados coerentes com a proposta que fizemos e, sobretudo, significativos para os estudos do texto.

\section{Editorial e argumentação}

A Linguística Textual, até meados da década de 70, em função do conceito de texto, visto como unidade linguística hierarquicamente mais elevada que a frase, preocupou-se basicamente com o estudo dos mecanismos interfrásticos. A maioria dos linguistas, na época, dedicou-se à construção de gramáticas do texto, tendo como objeto de estudo a coesão e a coerência.

Para Koch (2004), a Linguística Textual vem se tornando, na medida em que busca compreender e explicar o texto, um domínio multi e transdisciplinar, resultado de um complexo processo de interação social e também de construção social de sujeitos, de conhecimento e de linguagem. Linguagem que consideraremos, nesta pesquisa, como forma de ação e de interação entre os homens, concordando com Travaglia (1996), quando sintetiza tal concepção de linguagem, como segue:

[...] a linguagem como forma ou processo de interação. Nessa concepção o que o indivíduo faz ao usar a língua não é tão-somente traduzir e exteriorizar um pensamento, ou transmitir informações a outrem, mas sim realizar ações, agir, atuar sobre o interlocutor (ouvinte/leitor). A linguagem é, pois, um lugar de interação humana, de interação comunicativa pela produção de efeitos de sentido entre interlocutores, em uma dada situação de comunicação e em um contexto sócio-histórico e ideológico. Os usuários da língua ou interlocutores interagem enquanto sujeitos que ocupam lugares sociais e 'falam' e 'ouvem' desses lugares de acordo com formações imaginárias (imagens) que a sociedade estabeleceu para tais lugares sociais. (TRAVAGLIA, 1996, p. 7)

Nesse sentido, para a realização desta pesquisa, torna-se relevante ressaltar a concepção da linguagem como processo de interação que produz efeitos de sentido entre interlocutores por mostrar aos leitores de jornal que os editorialistas objetivam realizar ações por meio da linguagem. No caso 
específico deste estudo, a linguagem é tida como meio utilizado pelo enunciador (o editorialista), para estabelecer a interação verbal que se constitui como realidade fundamental da língua.

Segundo Guimarães (1995), na Semântica Argumentativa, a argumentação é vista como uma relação de sentidos na linguagem e essa relação não se dá com os objetos, mas orienta para uma interpretação em uma enunciação particular. O autor lembra as considerações da Retórica desde Aristóteles ou as de Platão e afirma que ao lado disso a gramática de Port-Royal foi decisiva para as questões da linguagem.

Koch (1984) afirma que pela linguagem, no processo de interação, procuramos a adesão de nosso interlocutor. Para a autora, os operadores argumentativos têm por função estruturar os enunciados em textos, orientando o sentido dos textos em uma dada direção.

Ducrot (1981) assevera que a marca da relação argumentativa pode ser encontrada na própria estrutura semântica. Para ele, na língua existem formas que, ao serem usadas, marcam a própria enunciação do enunciado.

Na concepção de Ducrot (1989), um morfema X é operador argumentativo em relação a uma frase $\mathbf{P}$ se três condições forem preenchidas: a) pode-se construir a partir de $\mathbf{P}$ uma frase $\mathbf{P}^{\prime}$, introduzindo-se $\mathbf{X}$ em $\mathbf{P}$, isto é, $\mathbf{P}^{\prime}=\mathbf{P}+\mathbf{X} ;$ b) em uma situação de discurso determinada, um enunciado de $\mathbf{P}$ e um de $\mathbf{P}^{\prime}$ possuem valores argumentativos nitidamente diferentes; c) a diferença argumentativa não pode ser derivada de uma diferença factual entre as informações fornecidas pelos enunciados de $\mathbf{P}$ e de $\mathbf{P}^{\prime}$. Por exemplo, no enunciado "Pedro trabalhou um pouco", pode-se substituir "um pouco" por "pouco" e construir uma frase $\mathbf{P}$ : "Pedro trabalhou pouco". É necessário dizer que $\mathbf{X}$ é operador argumentativo se um enunciado de $\mathbf{P}$ e um enunciado de $\mathbf{P}^{\prime}$ permitem conclusões diferentes. Mas as conclusões podem ser idênticas porque tudo depende do que se considera a melhor razão para o êxito. Se o pensamento for de que o trabalho leva ao êxito, toma-se $\mathbf{P}$ como argumento. Se for de que o trabalho leva ao fracasso porque cansa e irrita, o argumento será $\mathbf{P}^{\prime}$. O pesquisador desenvolve o conceito de "topos" proposto por 
Aristóteles na tentativa de fornecer condições de explicar os sentidos dos enunciados. Conclui que todo ato de argumentação e toda orientação argumentativa de um elemento semântico implicam que sejam convocados "topoi" graduais e que não se pode utilizar uma língua, na medida em que ela comporta operadores argumentativos, se não se pressupõe "topoi". Pode-se concluir do exposto que basicamente a argumentação consiste em reforçar a intensidade da adesão. Para isso, deve-se recorrer à noção de "lugares" ou "topoi argumentativos", proposta por Aristóteles. Os "lugares" podem ser definidos como depósitos de argumentos.

Nesse sentido, o estudo dos operadores argumentativos nos editoriais de jornal nos permitirá analisar de que jeito esses marcadores apresentam os enunciados que introduzem e o efeito de sentido que eles podem causar nos leitores.

A análise proposta enfatiza a importância da linguagem dos editoriais de jornal - principalmente em uma situação comunicativa polêmica - não só para a compreensão dos valores implicados no uso da língua, mas também como recurso que aponta razões plausíveis para a crença na ideia apresentada.

Dado o exposto, fica claro que para desenvolvermos nosso estudo, utilizaremos as contribuições da Linguística Textual e da Semântica Argumentativa, sobretudo nos traços relativos à argumentação e ao significado, aos operadores argumentativos e às técnicas argumentativas. Portanto, tornase importante apresentarmos, a seguir, alguns aspectos teóricos que tomamos como base de nossas análises e que são pertinentes para o nosso estudo: o editorial de jornal, a argumentação e as técnicas argumentativas.

\section{O editorial de jornal}

O editorial de jornal é produzido por um editor que tem a função de elaborar o texto dissertativo com argumentos baseados em uma ideia central, adequando-o aos valores que a instituição jornalística defende. $O$ texto não é assinado porque trata-se de uma opinião do jornal, por isso é escrito em 
terceira pessoa, em um espaço que busca conciliar contradições e interesses de diferentes leitores. Tem como tarefa assumir uma posição diante de fatos cotidianos marcantes e polêmicos da atualidade com a finalidade de exortar, analisar, comentar, criticar. Seu objetivo, portanto, é informar e relatar fatos sob sua subjetividade, pois evidencia o posicionamento do canal de comunicação. É um texto de opinião que pode aparecer na página de rosto do jornal ou internamente. De preferência, aborda assuntos polêmicos selecionados de acordo com o que se considera de interesse dos leitores do jornal. Segundo Erbolato (1981, p. 113),

os jornais mantêm páginas ou seções destinadas a emitir opiniões sobre assuntos em geral, já conhecidos dos leitores, quer anteriormente, quer pela leitura do noticiário do próprio dia. Mas, enquanto a maioria das páginas são dedicadas à apresentação imparcial dos acontecimentos, mostrados apenas interpretativamente, sempre ouvindo todas as partes possivelmente interessadas e sob ângulos diversos, a seção Editorial representa o pensamento do jornal.

A opinião do jornal é veiculada nos editoriais, que em enunciados decisivos realizam uma função textual, porque cumprem o papel social de apresentar um novo argumento ao leitor, na tentativa de convencê-lo e/ou persuadi-lo em relação à validade de sua opinião. Ao defender sua tese, o editorialista usa uma série de argumentos para construir o editorial, partindo de ideias organizadas e relacionadas umas às outras. Nos enunciados que direcionam a argumentação do editorial, estão presentes operadores argumentativos, marcas linguísticas que podem atuar como reforço ao ponto de vista que está sendo defendido.

Acreditamos que o editorialista, ao expressar a opinião do jornal a respeito do assunto de que trata, tem por finalidade fazer o leitor aderir seu ponto de vista. Para isso, busca despertar nele reflexões sobre as perspectivas propostas, na tentativa de conduzir o leitor a uma determinada conclusão. E o faz a partir de argumentos que conduzem ao posicionamento adotado pela instituição jornalística. Embora sejam características comuns a todos os textos de opinião, salientamos que o editorial é um texto argumentativo que se 
fortalece como formador de opinião pelo lugar/espaço que ocupa, pelo poder que a palavra impressa pode exercer ou não sobre o leitor e porque aborda questões atuais e polêmicas que envolvem a adesão ou não da sociedade.

Perelman e Olbrechts-Tyteca (1999) definem como textos argumentativos todos aqueles que objetivam fazer o outro mudar de postura, acreditar no que está sendo dito, ou então, fazer o que está sendo proposto. Isto é, fazer com que o outro mude o seu modo de pensar ou de agir. Por esse motivo, tomamos como referencial o Tratado da Argumentação de Perelman e Olbrechts-Tyteca (1999) com o objetivo de abordar em nossa análise as técnicas argumentativas que têm como finalidade obter a adesão do interlocutor. E no campo da Nova Retórica, ressaltamos a contribuição de Aristóteles no resgate e valorização da lógica do verossímil, pois ela distingue um dos campos de aplicação do raciocínio humano que se assenta em premissas prováveis e controversas.

\section{Argumentação}

A origem do termo argumento é latina, vem de argumentum, que tem como tema argu, cujo sentido é fazer brilhar, idêntico ao que aparece em argúcia, arguto. A argumentação, segundo Perelman e Olbrechts-Tyteca (1999), consiste na ação que se propõe a modificar um estado de coisas que já existem. A argumentação seria, pois, o ato de persuadir, de provocar uma escolha.

No editorial, como a intenção é manter a objetividade para que o texto seja persuasivo, a tarefa do grupo responsável pelo editorial é levar o leitor a adotar o mesmo ponto de vista, sensibilizando-o a se comportar na sociedade e atuar de acordo com os princípios e concepções defendidas por ele. Esse é um poder que o jornal tem e pode exercer ou não sobre seus leitores.

Dessa forma, os argumentos selecionados pelo locutor funcionam como fatores decisivos para a credibilidade do leitor. Por esse motivo, acreditamos que os operadores argumentativos estejam introduzindo, na maioria das vezes, 
determinados enunciados dos editoriais de jornal com o objetivo de fortalecer ainda mais a argumentação.

\section{Técnicas argumentativas}

As técnicas argumentativas são fundamentos que relacionam as teses de adesão inicial e a tese principal. Tratar de argumentação implica tratar de critérios relacionados à probabilidade do saber estabelecido e do que virá a ser instituído, isto é, à formação de opinião própria.

A necessidade da formação de opinião, em situação típica de argumentação coloca em pauta a ação da opinião, elemento designador daquilo em que se acredita.

A possibilidade de apresentar a opinião do jornal, por meio dos editoriais, abre possibilidades para o trabalho com a argumentação, ou melhor, para uma expressão mais autêntica sobre questões efetivas.

Para que as pessoas se entendam ao falar ou escrever é preciso agir retoricamente, ou seja, utilizar uma linguagem que as faça atingir os objetivos pretendidos na comunicação. Por esse motivo, são usadas técnicas de argumentação em que os argumentos produzidos podem ser verdadeiros ou não para justificar o ponto de vista adotado e fazer com que ele seja aceito, ou então para fortalecer ainda mais posições já aceitas.

Quanto às técnicas de argumentação, Perelman e Olbrechts-Tyteca (1999) destacam que o discurso persuasivo produz efeitos de sentido no enunciatário. Por esse motivo, pretendemos relacionar as técnicas argumentativas às funções que os operadores exercem nos editoriais. Esses aspectos nos interessam para a compreensão do papel argumentativo desses operadores. Refletiremos, ainda que de forma delimitada, sobre questões de natureza retórica e discursiva na análise que apresentaremos mais adiante.

$\mathrm{O}$ ato retórico pode se constituir, por exemplo, do critério pragmático (ou de efeito). É desse critério que vamos tratar em nossas análises. No critério pragmático, a retórica é vista como ação persuasiva que envolve efeitos 
pretendidos a partir das intenções do orador, de sua capacidade de reforçar valores de um auditório ou mudar sua opinião.

Entendemos o discurso retórico como aquele que propõe uma visão da realidade a partir das necessidades do orador e dos interesses de seu auditório. Nesse sentido, a qualidade da argumentação é uma estratégia do orador que deve auxiliá-lo para que tenha a adesão do auditório e que haja credibilidade em sua argumentação. Dessa forma, a função retórica contribui para enfatizar os interesses do auditório e também para reforçar a opinião de um determinado grupo. Ela pode, assim, usar certos recursos para garantir a eficácia da comunicação.

Na constituição da opinião, de acordo com postulados preconizados por Aristóteles e retomados por Perelman e Olbrechts-Tyteca (1999), procede-se à divisão das técnicas argumentativas que compreendem dois grupos principais: as que utilizam argumentos quase-lógicos (que se preocupam com "verdades" para o homem em geral) e as que trabalham com argumentos baseados na estrutura do real (que não estão ligados à descrição objetiva dos fatos, mas a opiniões relativas a eles).

Os argumentos quase-lógicos apoiam-se em princípios lógicos, em premissas pré-existentes. Os argumentos baseados na estrutura do real têm seus princípios nas experiências, nas relações reconhecidas entre as coisas. Restringimos nosso estudo a esses argumentos, por atenderem ao propósito de análise que objetivamos.

\section{Argumentos quase-lógicos}

1) Comparação - a argumentação que parte da comparação coteja vários objetos para avaliá-los um em relação ao outro. Por isso, esse argumento se distingue tanto dos argumentos de identificação, quanto dos por analogia. As comparações podem ser por oposição (pesado e leve), por ordenamento (o que está mais pesado que) e por ordenação de quantidade (por exemplo, pesagem por meio de unidades de peso). 
2) Compatibilidade/ Incompatibilidade - ao usar essa técnica, a pessoa que argumenta tem por objetivo demonstrar que a tese de adesão inicial, com a qual o auditório concordou previamente, é compatível ou não com a tese principal.

3) Regra de Justiça - esse argumento é fundamentado no tratamento idêntico a seres e situações que façam parte de uma mesma categoria.

4) Retorsão - é uma réplica feita a partir dos próprios argumentos do interlocutor.

5) Ridículo - esse argumento consiste em criar uma situação irônica, quando da adoção, de forma provisória, de um argumento, extraindo dele todas as conclusões, por mais absurdas que sejam.

As definições, usadas como técnicas argumentativas, podem ser:

a) Lógicas - possuem uma definição própria que a distingue de todas as outras.

b) Expressivas - não têm compromisso com a lógica, dependem de um ponto de vista.

c) Normativas - indicam o sentido que se quer dar a uma palavra em um discurso e dependem de um acordo feito entre o locutor e o auditório.

d) Etimológicas - são fundamentadas na origem das palavras.

\section{Argumentos fundamentados na estrutura do real}

6) Pragmático - esse argumento se fundamenta na relação de dois argumentos sucessivos por meio de um vínculo causal. $O$ argumento pragmático é a consequência nessa relação.

8) Desperdício - é um argumento que consiste em dizer que uma vez que um trabalho foi iniciado, é preciso que seja concluído para não se perder o tempo e o investimento.

9) Exemplo - essa argumentação acontece quando há a sugestão da imitação das ações de outras pessoas, que podem ser célebres, membros da família, conhecidas, cuja conduta é admirada. 
10) Ilustração - a ilustração possui como função reforçar a adesão a uma regra conhecida e aceita, fornecendo casos particulares que podem esclarecer o enunciado geral.

11) Modelo/Antimodelo - o argumento pelo modelo é uma variação da argumentação pelo exemplo. A argumentação pelo antimodelo fala naquilo que deve ser evitado.

12) Analogia - esse argumento utiliza como tese de adesão inicial um fato que possui uma relação analógica com a tese principal.

13) Autoridade - é o argumento que utiliza atos ou juízos de uma pessoa ou de um grupo de pessoas como meio de prova a favor de uma tese. $\mathrm{Na}$ maioria das vezes, o argumento de autoridade, em vez de constituir-se como a única prova, pode completar uma rica argumentação. Então, quanto mais importante e bem aceita é a autoridade, mais importante são suas palavras.

Cabe-nos ressaltar que, sendo o editorial uma forma de expressão do jornal que tem o poder de usar argumentos com intenções de levar o leitor a concordar com a opinião veiculada, a análise das técnicas argumentativas que utiliza na sua comunicação, aliada ao uso dos operadores argumentativos, pode apontar seus efeitos de sentido.

\section{Argumentando nos editoriais - análise e resultados}

A investigação que fizemos encontrou e considerou os seguintes grupos de operadores indicados com seu papel básico:

$1^{\circ}$ grupo - além disso, além de, e, também, ainda, e se (operadores que acrescentam mais um argumento que passa a ser decisivo, quando há duas (ou mais) escalas orientadas no mesmo sentido, introdutores de mais um argumento a favor de uma determinada conclusão ou marcadores de tempo)

$2^{\circ}$ grupo - até (operador que estabelece a hierarquia dos elementos em uma escala, assinalando o argumento mais forte para uma conclusão, ou então o mais fraco, deixando subentendido que existem outros mais fortes)

$3^{0}$ grupo - mas, porém (assinalam uma oposição entre argumentos implícitos ou explícitos) 
40 grupo - portanto, só então (apontam a conclusão a argumentos apresentados anteriormente).

$5^{\circ}$ grupo - afinal, pois (introduzem um ato de justificativa ou explicação ao enunciado anterior, estabelecem uma relação de causa/consequência)

$6^{\circ}$ grupo - tanto que (operador que serve para estabelecer relações de comparação entre elementos, tendo em vista uma conclusão)

70 grupo - já, menos de (marcadores de tempo ou mudança de estado)

$8^{\circ}$ grupo - se (marcador de condição)

90 grupo - naturalmente, comprovadamente (advérbios de atitude que têm como função esclarecer, confirmar ou enfatizar um ato de asserção anterior ou posterior)

$10^{\circ}$ grupo - por exemplo (operador que estabelece relação de especificação e/ou exemplificação)

$11^{\circ}$ grupo - como (operador que exprime uma relação de conformidade)

$12^{\circ}$ grupo - nem (marcador que exprime uma relação de negação)

Como podemos detectar nos editoriais transcritos no próximo item, há uma alta frequência de uso de operadores no gênero textual editorial de jornal. Isso pode significar que essa categoria de texto precisa orientar bem o leitor para a conclusão a que deve chegar e, ainda, de acordo com Agustini (informação verbal ${ }^{* 2}$ ) achar/ter a impressão de que chegou a essa conclusão porque raciocinou por conta própria; daí advindo a logicidade da argumentação.

Expomos, a seguir, como se dá o processo de argumentação, em relação às técnicas argumentativas usadas.

\section{Análise das técnicas argumentativas em três editoriais do corpus}

Para a presente fase da análise, transcrevemos e analisamos três editoriais, um de cada jornal e todos três referentes ao mesmo assunto: a votação, pela Câmara dos Deputados, da Lei de Biossegurança.

\footnotetext{
${ }^{2}$ Consideração tecida pela Profa Drạ Carmen Lúcia Hernandes Agustini, durante o exame de qualificação da dissertação "Um estudo do uso de operadores argumentativos no gênero editorial de jornal", realizado na Universidade Federal de Uberlândia (UFU).
} 
Procuramos evidenciar neles tipos de argumentos, cujos esquemas argumentativos têm como base os estudos de Perelman e Olbrechts-Tyteca (1999) e apresentar as funções dos operadores argumentativos como correspondentes aos lugares da Retórica.

A Retórica, na concepção de Aristóteles, trata de questões que de algum modo são da competência de todos os homens, na medida em que se empenham, dentro de determinados limites, a defender uma tese, em apresentar uma defesa ou uma acusação. Na ótica de Aristóteles, à Retórica cabe descobrir os meios que, relativamente a qualquer argumento, podem levar à persuasão de um determinado auditório. No raciocínio retórico, as premissas são extraídas de certos lugares (ou topos) que se estendem a todos os temas, pois são gerais, como o lugar da quantidade, do preferível, o lugar da proporção, o lugar da causa e do efeito, e outros; ou que se constituem de determinados temas que funcionam como verdades particulares, aceitas por todos. A tarefa da Retórica é, conforme assinalou Lopes (2005), persuadir, convencer, agradar, manipular ideias com a finalidade de aceitação, descobrir as intenções de quem fala ou escreve, atribuir razões ao seu dizer.

Nessa análise, vamos circunscrever o sentido de Retórica àquele reservado aos estudos das técnicas discursivas, que correspondem aos atos e aos fatos enquanto mecanismos utilizados na língua para harmonizar seus interesses com os dos outros, por meio de raciocínios argumentativos, com a finalidade de persuadir. Nesse sentido, consideramos ser de fundamental importância para o orador começar por conhecer quais as teses e os valores inicialmente admitidos por seu auditório, pois eles deverão constituir o ponto de partida do discurso.

As análises que fizemos levam-nos a acreditar que os editoriais jornalísticos atestam a ideologia de cada jornal a que pertencem, e o fazem por meio de técnicas argumentativas adotadas pelos seus autores com a finalidade de persuadir. Fato que nos permite evidenciar que existe um ethos cultural (conjunto dos traços de caráter que o orador deve revelar ao auditório para causar boa impressão), constituído para o editorial e que as interpretações que 
fazemos dos argumentos estão condicionadas aos topói (lugares retóricos) e à formação do sujeito-histórico-social.

Consideramos o ethos, nos editoriais, conforme Reboul (1998), como o caráter (psicológico) dos diferentes públicos, aos quais o orador deve adaptarse. Para o autor o ethos diz respeito ao orador, pathos ao auditório, o logos à argumentação propriamente dita do discurso. Assim, um discurso é retórico quando, para persuadir, alia a argumentação ao seu componente oratório.

Segundo Perelman e Olbrechts-Tyteca (1999), para fundamentar valores e hierarquias ou reforçar a intensidade da adesão que os lugares retóricos suscitam, é permitido relacioná-los com outros valores ou hierarquias para consolidá-los ou recorrer aos topói (lugares). Para Reboul (1998), a leitura retórica é um diálogo. Mesmo que ela não tenha como objetivo dizer que o texto tem ou não tem razão, ela não é neutra, pois faz juízos de valor, mostra que tal argumento é forte ou fraco, que tal conclusão é legítima ou errônea.

Sendo assim, passemos à análise de argumentos usados no primeiro texto selecionado:

\section{TEXTO 1}

\section{Contra o tempo}

Um argumento habitualmente usado pelos oponentes do emprego de células-tronco embrionárias no tratamento de uma série de doenças é que a cura por esse tipo de terapia, longe de estar ao alcance da mão, não passa de uma duvidosa possibilidade. Esse raciocínio em si não é convincente: afinal, se é distante a perspectiva de encontrar tratamento eficaz para doenças hoje incuráveis, isso não pode justificar o abandono das pesquisas. Além disso, a argumentação acaba de sofrer um golpe devastador com a notícia procedente da Itália, de que um menino de 5 anos de idade foi curado de uma forma de anemia potencialmente fatal, a talassemia, com células-tronco extraídas da placenta de seus irmãos gêmeos recém-nascidos.

Nesse caso, naturalmente, não estavam em jogo as complexas questões éticas relativas à retirada de células-tronco de embriões, que morrem no 
processo. Mas esta foi uma situação singular, que não pode ser repetida à vontade; a utilização de células embrionárias continua a ser o ponto-chave do debate. Tanto que na Inglaterra, que tem estado na vanguarda nas pesquisas e na legislação sobre a matéria, os pais de um menino que sofre também de uma forma rara e potencialmente letal de anemia foram autorizados a produzir e selecionar 12 embriões especificamente para extrair células-tronco geneticamente compatíveis com a criança.

Como se vê, bem mais rapidamente do que se esperava a situação está passando dos debates e estudos teóricos para a prática médica. 0 que ainda há pouco era classificado de vaga promessa já começa a dar resultados concretos notáveis.

Essa mudança de panorama deixa claro também que a Lei de Biossegurança não pode ficar indefinidamente parada no Congresso Nacional. Os parlamentares precisam atentar para o fato de que as células-tronco já estão começando a produzir curas, e criar condições para que os pesquisadores brasileiros possam trabalhar sem impedimentos.

Temos comprovadamente competência científica suficiente para acompanhar os países mais desenvolvidos nessa área. Mas corremos o risco de ficar para trás se faltar o devido amparo da legislação. (O Globo, Rio de Janeiro, 10 set. 2004, Ano 79, n. 25967, Editoriais, p. 7).

No texto 1 , observamos a presença de 14 (quatorze) operadores argumentativos. Nele discute-se a questão da Lei de Biossegurança, enfatizando-se a importância da retirada de células-tronco de embriões para pesquisas.

No primeiro parágrafo do texto, o enunciador cita um argumento contrário à sua opinião. Em seguida, afirma que o argumento não é convincente, usando em um primeiro momento o operador afinal para justificar a afirmação que fez antes. A seguir, usando o operador se para evidenciar sua tese (ideia defendida), afirma que o fato de ainda não ser possível a cura por meio do emprego de células-tronco embrionárias, não é argumento para o 
abandono das pesquisas. Ao finalizar o parágrafo, usa o operador além disso para introduzir mais um argumento com a finalidade de comprovar a invalidade da argumentação que está criticando.

O editorialista discorda da visão das pessoas que se opõem ao emprego de células-tronco embrionárias no tratamento de doenças. A escolha do se introduz a explicação que o editorialista julga necessária para o convencimento do leitor (seu auditório). No período seguinte do texto, quanto ao lugar da argumentação, conforme Aristóteles concebe, o editorialista, buscando a adesão do auditório, cita um caso particular de cura como argumento por ilustração. Esse argumento possui como função reforçar a adesão a uma regra conhecida e aceita, fornecendo casos particulares que podem esclarecer o enunciado como um todo. Torna-se importante ressaltar que o argumento por ilustração não depende de adesão à regra, ele pode ser duvidoso, mas deve impressionar a imaginação para se impor à atenção.

No segundo parágrafo do texto, o editorialista comenta, introduzindo a ideia, por meio do operador naturalmente, que o menino só foi curado porque não estavam em jogo questões éticas. Em seguida, para reforçar sua tese inicial (de que as pesquisas com células-tronco devem ser permitidas), ele usa o operador mas, e lançando mão do argumento por compatibilidade/ incompatibilidade afirma que a não utilização de células-tronco continua a ser um entrave para a cura de doenças, ou seja, o debate sobre questões éticas tem que acabar porque o uso das células-tronco, comprovadamente, é eficaz. Depois, com o uso dos operadores tanto que e também o editorialista usa o argumento por ilustração, ao fornecer um caso particular ocorrido na Inglaterra para tentar comprovar o que ele defende como melhor solução.

No terceiro parágrafo do texto, o editorialista inicia o parágrafo usando o como com valor de conformidade para tentar comprovar que a situação já está mudando. Usa o operador ainda para introduzir o argumento que considera mais forte para causar no leitor a adesão à sua tese e para finalizar a argumentação, assinala a mudança de estado, usando o operador já para afirmar que os resultados são notáveis. 
Continua, no quarto parágrafo, a valorizar o efeito do emprego das células-tronco para a sociedade. Nesse sentido, o editorialista organiza seu raciocínio pelo argumento pragmático (que se fundamenta na relação de dois argumentos sucessivos por meio de um vínculo causal), que permite a ele apreciar a proposta das pesquisas com células-tronco como um ato favorável à cura de doenças, já que pôde ilustrar no texto essa afirmação. Escolhe, para justificar seu ponto de vista, as seguintes marcas linguísticas: ainda e já. E não deixa de, ao finalizar o texto, com o uso de comprovadamente, talvez por acreditar que conseguiu, com as ilustrações que fez, a adesão de seu "auditório", seguido de mas, deixar uma opinião, um ponto de vista: o de que corremos o risco de ficar para trás se a lei não permitir que as pesquisas sejam realizadas.

O posicionamento do editorialista revela um raciocínio concebido em função de suas consequências, que nesse caso são os resultados concretos notáveis da utilização das células-tronco embrionárias e o possível atraso da ciência no Brasil.

Nesse sentido, podemos observar que o editorial está imbuído, como Reboul (1998) afirma, da importância do ethos, pois o editorialista manifesta de forma confiante seu ponto de vista, porque sabe que pode contar com a credibilidade do auditório. Sabemos que sem essa confiança, sejam quais forem seus argumentos, não há a menor possibilidade de persuasão. Daí vem a importância de, cada vez mais, não só nos jornais, mas em outros meios de comunicação, o conhecimento do auditório não poder ser ignorado pelo orador.

Notamos que a construção retórica do discurso, nesse editorial, exigiu que os argumentos fossem sustentados por "provas", baseadas em julgamento de valor retórico da legitimação.

Passemos à leitura e análise da argumentação no segundo texto:

TEXTO 2

Avanço para a ciência 
São bem-vindas as emendas introduzidas pelo senador Osmar Dias (PDT-PR) no projeto da Lei de Biossegurança que tramita no Senado. Elas permitem a pesquisa com células-tronco embrionárias, que está na base da terapia celular e da chamada clonagem terapêutica. Na versão do projeto que veio da Câmara, por força dos lobbies evangélico e católico, esse tipo de investigação foi, para efeitos práticos, proibido.

As terapias que usam células-tronco são uma das principais promessas da ciência para o tratamento de diabetes, mal de Parkinson e outras doenças degenerativas, além de trazer a perspectiva de que, um dia, laboratórios possam desenvolver órgãos para transplantes.

O princípio geral é o de que células-tronco embrionárias conservam a capacidade de converter-se em qualquer tipo de tecido, de pele a ossos. A objeção religiosa deve-se ao fato de que, para obter as células-tronco, é necessário destruir embriões na fase de blastocistos -um aglomerado de cerca de uma centena de células. Já existe algo como 20 mil embriões nessas condições congelados em clínicas de fertilidade. Muitos deles serão destruídos de qualquer forma, pois são sobras de processos de fertilização in vitro.

As alterações propostas ainda ficam aquém do desejável, ao não prever, por exemplo, a possibilidade de que, no futuro, células-tronco embrionárias sejam produzidas a partir de tecidos do próprio paciente, contornando assim o problema da rejeição. Não há dúvida, porém, de que o substitutivo agora aprovado na Comissão de Educação do Senado representa um enorme avanço em relação ao texto anterior.

Não se preveem maiores problemas para o projeto ser sancionado pelo Senado, hipótese em que voltaria à Câmara - onde se concentram os lobbies contrários. Portanto, se o governo não se mobilizar para garantir a pesquisa com células-tronco, o país corre o risco de ser condenado ao atraso numa área vital da ciência. (Folha de S. Paulo, São Paulo, 11 ag. 2004, Ano 85, n. 25524, Editoriais, p. 2.) 
Ao ler o texto, que possui 08 (oito) operadores argumentativos, percebemos que no início o editorialista considera "bem-vindas" as emendas do projeto a favor de pesquisas com células-tronco embrionárias, que se encontram na base da terapia celular e da clonagem terapêutica. Ainda no primeiro parágrafo do texto, ele informa que, na versão do projeto que veio da Câmara, a investigação foi proibida. Podemos notar que até aquele momento nenhum operador argumentativo fora usado.

Em seguida, ao iniciar o segundo parágrafo do texto, para reforçar a afirmação de que as terapias com células-tronco são uma das principais promessas da ciência, o editorialista usa um operador argumentativo: além de. Esse operador exerce a função de adicionar um argumento para uma conclusão, ou seja, é usado como estratégia argumentativa que busca levar o leitor à adesão da tese inicial: de que as pesquisas precisam ser viabilizadas. 0 emprego do operador além de aciona a justificativa que torna mais significativa a adesão do leitor à opinião que o editorial encerra, característica do argumento pragmático, cuja função é reforçar a adesão.

Os operadores já e pois, são usados para introduzir o argumento por ilustração, já que apresentam um dado estatístico sobre o uso de células de embriões em clínicas de fertilização. A tese de adesão inicial é retomada no quarto parágrafo, quando há a afirmação de que as alterações ainda ficam aquém do desejável. O uso de por exemplo serve para introduzir a opinião do editorialista, o seu ponto de vista sobre as propostas que ainda estão aquém do desejável. No período seguinte, o editorialista continua a expor suas ideias, elegendo o operador argumentativo de oposição, porém, para novamente apontar a certeza de que o substitutivo aprovado no Senado representa um enorme avanço.

Ao concluir seu raciocínio, no último parágrafo do texto, por meio dos operadores, portanto e se, introduz o argumento que pode levar o leitor a refletir sobre a necessidade da adesão às pesquisas para que o país não fique atrasado cientificamente. Nota-se, pelo emprego do operador condicional se, 
que o editorialista pressupõe que o governo pode estar atrapalhando o avanço da ciência. Esses indícios nos remetem novamente ao argumento pragmático.

Os argumentos apresentados têm uma intenção: levar o leitor a acreditar que é preciso avançar nas pesquisas, como o próprio título do editorial já indica.

Vimos em Perelman e Olbrechts-Tyteca (1999), que o ato retórico serve para fazer alguém mudar de ideia, como também para fortalecer posições já existentes, para reforçar e fortalecer a opinião que todos já formaram sobre determinada ideia. Nesse sentido, a análise revela que o discurso apresentado pelo editorialista procura reafirmar a posição de um determinado grupo cultural que ele parece conhecer bem.

Vejamos a argumentação no terceiro texto:

\section{TEXTO 3}

\section{A questão dos transgênicos}

Depois de repetir, mais de uma vez, que não assinaria medida provisória para facilitar o início do plantio da safra de 2004-2005 de soja transgênica, o presidente Luiz Inácio Lula da Silva efetivou o ato. Até parece que ninguém sabe que há mais de seis anos os sojicultores estão adquirindo sementes modificadas nas fronteiras do País, em especial os gaúchos. $O$ texto da medida provisória é simples, a fim de não colidir com a Lei de Biossegurança, que ainda depende de votação na Câmara dos Deputados, para só então ir à sanção presidencial.

Foi a terceira vez em menos de dois anos que se recorre a esse mecanismo para liberar a venda de soja modificada e permitir o plantio da safra. O que se constata, portanto, é que, no embate entre o ministro da Agricultura, Pecuária e Abastecimento, Roberto Rodrigues (abertamente a favor), e a sua colega do Meio Ambiente, Marina Silva (explicitamente contra), o primeiro acabou vitorioso, sem se discutir realmente se a soja transgênica é $100 \%$ segura para a saúde humana e se exerce alguma influência negativa, ecologicamente. A dúvida nem é cabível, pois todo mundo sabe - até o mais 
humilde lavrador no Alto Amazonas - que a monocultura é prejudicial ao meio ambiente e pode comprometer a própria natureza.

O problema foi resolvido temporariamente - mal resolvido, diga-se de passagem -, mas nada indica que chegou ao fim o longo debate que vem sendo deixado de lado, por altos interesses das multinacionais das sementes e do agrotóxico. Um ministro (não identificado) do Supremo Tribunal Federal (STF) disse que não se pode reclamar da demora de uma decisão judicial. E acusa a Justiça de autismo, quando analisa o caso. Deu como exemplo a decisão do Tribunal Regional Federal (TRF): os desembargadores reconheceram a competência da CNTbio para liberar o plantio dos transgênicos da linha Roundup Ready (favorável à Monsanto). Mas os mesmos desembargadores mantiveram a proibição da soja da multinacional. Uma questão que não podia demorar tanto acabou confundindo o meio rural. Parcela ponderável teme que o Brasil pode perder mercado na União Europeia, que historicamente não permite a comercialização de grãos geneticamente modificados em sua jurisdição e insistem que o Brasil deve manter o plantio tradicional. Agora, vão exigir que a soja transgênica seja identificada com embalagem especial, com advertência em letras garrafais, para não ser confundida com a natural. Quem sabe dos métodos aplicados nesse mercado altamente competitivo pode imaginar que não será difícil contaminar plantações tradicionais. Se é público que há contrabando de sementes, tudo o mais é livre, lamentavelmente. A previsão é que a produção de soja, com o reforço das sementes modificadas, será de 65 milhões de sacas na safra a ser colhida em 2005. (Estado de Minas, Belo Horizonte, 18 out. 2004, n. 22939, Editoriais, p. 2).

Nesse texto temos 14 (quatorze) operadores argumentativos. Ele se inicia com a narrativa de um fato intrigante: que o presidente Lula assinou a medida provisória para facilitar o início do plantio da safra 2004-2005 de soja transgênica. E usa, para contar o fato, o operador que estabelece relação de proporção mais de para causar no leitor o efeito de sentido da perplexidade 
diante do fato de que, mais uma vez, o governo é obrigado a assinar uma medida provisória.

A afirmação introduzida pelo operador argumentativo até, de que há mais de seis anos os sojicultores estão adquirindo sementes modificadas nas fronteiras do País, em especial os gaúchos, constitui-se como um argumento por ilustração.

O segundo período do texto - que chega a ser irônico - é introduzido pelo operador até. Esse operador assinala um argumento que dá prosseguimento à declaração feita anteriormente, reforçando-o e objetivando persuadir o leitor a aderir à ideia defendida de que já está passando da hora de regulamentar o plantio da soja transgênica. Em seguida, o editorialista usa os operadores ainda e só então para apresentar o problema que precisa ser solucionado: a aprovação da Lei de Biossegurança.

No segundo parágrafo usa argumentação semelhante à do primeiro. Usa também um operador que estabelece relação de proporção, só que agora menos de, para salientar que a votação precisa ser feita porque já é a terceira vez que se lança, em relação ao assunto, uma medida provisória. Dando continuidade à sua argumentação, o editorialista recorre a portanto, se, e se, nem, pois para introduzir argumentos que chamam a atenção do leitor, principalmente para o fato de que discussões importantes sobre a soja transgênica não são preocupações dos ministros da Agricultura e do Meio Ambiente.

É interessante ressaltar aqui que os três textos escolhidos para essa análise tratam do mesmo assunto e só esse abordou fatos tão importantes para o debate que envolve a aprovação da Lei de Biossegurança. Também no último argumento do segundo parágrafo usa-se o operador até, que introduz um argumento decisivo sobre a soja transgênica ser segura para a saúde humana ou não: de que todo mundo sabe, até o mais humilde lavrador, que a monocultura é prejudicial ao meio ambiente e pode comprometer a própria natureza. $O$ argumento que o operador introduz, novamente, é o da ilustração, 
que pretende persuadir o auditório (o leitor) e fazer com que concorde com o raciocínio do enunciador do texto.

A seguir, o editorialista continua a evidenciar questões em torno da tese defendida. Ele estabelece uma linha de raciocínio baseada em provas que podem justificar sua adesão à tese inicial, como marca de argumento pragmático, ainda que de forma difusa.

Os operadores e e mas, no último parágrafo, introduzem argumentos concretos associados a pontos de vista do editorialista. Esses operadores são usados, ao nosso ver, com o objetivo maior de informar sobre o assunto. E consideramos que essa pode também ser uma estratégia, já que muito antes, desde Aristóteles, acredita-se que levar o auditório a raciocinar junto pode ser uma forma eficaz de conseguir a adesão.

Os discursos, nos três editoriais, ao que parece, foram organizados numa dada situação retórica, cuja identidade é representada nos lugares retóricos, a partir de premissas evidentes para os editorialistas, mas que se constituem como hipóteses. Os lugares retóricos revelam o caráter cultural dos editorialistas e a maneira como procuraram expor seu ponto de vista, partindo do consenso com o auditório.

Em seus enunciados, os editorialistas usam operadores argumentativos que se constituem como manobras discursivas adotadas pelos editorialistas com a intenção de reforçar a persuasão, de causar no leitor a adesão ao ponto de vista que possuem. Cumpre frisar que o discurso formador do editorial tem 0 poder de direcionar o pensamento do leitor e se encontra imbuído de um caráter ideológico.

Nessa direção, os resultados obtidos indicam a necessidade de uma maior atenção ao estudo das funções que os operadores argumentativos exercem em textos argumentativos e do ensino das estratégias argumentativas pautadas na Nova Retórica, no Ensino Médio. Isso não significa abandonar outros estudos, mas aprimorar os estudos de Língua Portuguesa.

A partir da análise que fizemos, chegamos a confirmações pertinentes em relação ao uso das técnicas argumentativas nos editoriais e ao efeito de 
sentido que podem causar no leitor do jornal e, consequentemente, na sociedade da qual esse leitor faz parte:

a) que os argumentos, em que se usam operadores argumentativos, apontam uma descrição dos fatos ligada a pontos de vista que chamam a atenção e podem levar à mudança de opinião do leitor e ao abandono do modo como via o tema antes de ler o editorial;

b) que o leitor é visto como alvo que pode ser conduzido a aderir à tese defendida pelo editorialista, reforçada pelo uso dos operadores argumentativos, na tentativa de facilitar as mudanças sociais, tornando-as mais naturais quando ocorrem.

Editorial, operadores argumentativos e tipos de argumento

Para uma melhor visualização do que ocorreu nos editoriais analisados apresentaremos, a seguir, o resultado do levantamento dos tipos de argumentos encontrados nos editoriais analisados, introduzidos pelo uso de operadores argumentativos. Oportunamente, ressaltamos novamente que os enunciados analisados que contêm os operadores, podem ser analisados de outras maneiras, de acordo com outros planos de delimitação.

Conforme o levantamento que fizemos, chegamos à constatação de que, em relação ao uso das técnicas argumentativas nos editoriais, os temas tratados nos editoriais, em geral, são apresentados a partir do argumento pragmático, cuja função é reforçar a adesão pelas consequências de algo. Nele o editorialista hierarquiza as relações de causa e consequência para sustentar seu ponto de vista na tentativa de persuadir o auditório.

Torna-se importante ressaltar a preferência que os editorialistas do jornal O Globo têm pelo uso do argumento pragmático - em que o editorialista pode hierarquizar as relações de causa e consequência como estratégia para justificar o seu raciocínio.

O segundo tipo de argumento mais usado foi o argumento por ilustração. Na verdade, esse argumento precisa impressionar a imaginação do leitor para chamar a atenção. Dessa forma, quanto mais concreto for, mais facilitará a 
compreensão das teses defendidas pelo editorialista, podendo se tornar mais forte para levar à adesão.

Ao usar o argumento da compatibilidade/incompatibilidade com tanta frequência, pois ele é o terceiro tipo de argumento mais usado nos três textos, o editorialista pode ter como finalidade se aliar ao senso comum. Em seguida, após "ser aceito pelo leitor" e até mesmo "ganhar sua confiança", o produtor do texto pode analisar os fatos tendo em vista o valor do auditório/leitor com a finalidade de, ao tentar convencer o leitor ou fazê-lo concordar com a tese de adesão inicial, tornar-se mais persuasivo. Nesse sentido, é bom lembrar que muitas pessoas não têm opinião formada sobre certos assuntos, assim as possibilidades de persuasão aumentarão se o editorialista usar argumentos que estejam o mais próximo possível da realidade para que eles possam se constituir como "verdades" para o auditório.

Podemos incluir, entre os argumentos mais usados (pragmático, por ilustração e por compatibilidade/incompatibilidade) - responsáveis pela quase totalidade dos argumentos usados, a definição. A definição expressiva foi a mais usada, e ela não tem compromisso com a lógica, pois depende de um ponto de vista. Essa técnica argumentativa permite a fixação de pontos de vista como teses de adesão inicial. Aí podemos pensar que para o argumento do editorialista ser aceito ou não, tudo vai depender de sua expressividade. Assim, quanto mais forte for o argumento, maior poderá ser a adesão.

De acordo com o levantamento que fizemos, os quatro argumentos, pragmático, por ilustração, por compatibilidade/incompatibilidade e definição são responsáveis pela quase totalidade dos argumentos usados. Isso parece ser bastante significativo quando se trata de caracterizar os editoriais enquanto gênero de base argumentativa.

A partir levantamento feito, objetivamos verificar os efeitos de sentido causados por argumentos introduzidos pelo uso de operadores argumentativos no discurso jornalístico, no leitor e, consequentemente, na sociedade. Pudemos observar que: 
a) o centro de interesse do leitor do editorial são os temas polêmicos ligados, principalmente, a assuntos políticos, econômicos e aos avanços da ciência bem como das leis que regem a vida humana e as possíveis mudanças que podem ocorrer;

b) os argumentos usados, geralmente descrevem fatos ligados a pontos de vista que podem levar à mudança de opinião do leitor e ao abandono do modo como visualizava as questões relacionadas ao tema antes de ler o editorial;

c) o leitor é visto como alvo que pode ser conduzido a aderir à tese defendida pelo editorialista, reforçada pelo uso dos operadores argumentativos, na tentativa de facilitar as mudanças sociais, tornando-as mais naturais quando ocorrem;

d) o discurso apresentado pelo editorialista procura reafirmar a posição de um determinado grupo cultural que ele já conhece bem;

e) o posicionamento do editorialista revela um raciocínio concebido em função, sobretudo, de suas consequências e de fatos que ilustram proposições gerais.

\section{Considerações finais}

A partir da Semântica Argumentativa e da Linguística Textual, desenvolvemos um estudo da argumentação, investigando o uso de operadores argumentativos nos editoriais de jornal, tendo em vista que eles funcionam como estratégias argumentativas que têm por objetivo levar o leitor a concordar com determinado ponto de vista adotado pelo jornal e apresentado pelo editorialista.

Verificamos que a linguagem do editorial tem características próprias que objetivam chamar a atenção do leitor e induzi-lo a aceitar ou não levar a tese defendida pelo editorialista, por causa do peso que tem enquanto palavra impressa. Constatamos que o valor argumentativo de uma frase não é somente uma consequência das informações que ela traz, mas dependendo de como ela 
for construída - comportando diversos morfemas, expressões ou termos - além de informar, pode servir para dar uma orientação argumentativa ao enunciado.

Constatamos ser frequente $\mathrm{o}$ uso de operadores argumentativos em editoriais de jornal. Comparando o número de ocorrências de operadores argumentativos por jornal e também os percentuais de operadores encontrados neles, afirmamos que apontam para um similar estilo de escrita. De uma maneira geral, existe um equilíbrio no uso dos operadores argumentativos que funcionam como marcas linguísticas na superfície do texto, contribuindo para tornar a argumentação mais forte e, sobretudo, mais eficaz.

A análise feita permite-nos afirmar que é característica do próprio gênero editorial expressar o ponto de vista do jornal a partir de interesses. Isso pode explicar as escolhas dos assuntos tratados, ou seja, aquilo que estão valorizando mais, o silenciamento diante de certos acontecimentos ou uma importância enorme dada a determinados fatos acontecidos na sociedade. 0 que nos remete à afirmação que fizemos no início desta pesquisa, de que o que se apresenta escrito é uma espécie de representação da realidade porque passou por um deslocamento. Na verdade, pode levar-nos a perceber que é característica do gênero editorial de jornal recortar fragmentos da realidade e os transferir para o universo do jornal, interpretando a realidade. $E$, como percebemos nas análises feitas na pesquisa, os editoriais podem conseguir ou não a adesão do leitor, a partir de estratégias que contribuem para a persuasão.

Acreditamos que $O$ estilo de escrita semelhante dos três jornais - $O$ Globo, Folha de S.Paulo e O Estado de Minas - deve-se ao fato de que o editorialista precisa seguir o manual de instruções do próprio jornal para a produção do texto e, ao redigi-lo e editá-lo, precisa tomar decisões que são subjetivas, isto é, que contemplem o modo de pensar e analisar de cada grupo responsável pelos assuntos polêmicos tratados em seus editoriais. Na pretensão de fazer crer que está com a razão, cada grupo apresenta um discurso ideológico influenciado por razões impostas pelo jornal por causa da linha de pensamento adotada enquanto instituição. 
A presença de operadores argumentativos nos editoriais mostrou-se de grande importância na fundamentação de valores e hierarquias ou reforço da intensidade da adesão que os lugares retóricos suscitam. Revelou também que o emprego desses termos/marcas não se faz por uma mera escolha, mas, com certeza, tem um objetivo: tornar "mais fortes" as opiniões que devem ser acolhidas pelo auditório (o leitor) que sai, muitas vezes, dizendo a outras pessoas que leu o que está falando e nem se dá conta de que, dessa forma, está não só transmitindo o que leu, mas também está assumindo a "ideia lida" como sua. Isso vai fazendo com que ele "aceite" com maior facilidade as mudanças sociais, econômicas e políticas, ou relacionadas à ciência.

Verificamos que, de acordo com as funções mais frequentes encontradas e introduzidas principalmente pelos operadores e e mas, as estratégias básicas da argumentação dos editoriais são: introduzir um argumento apresentado como acréscimo e contrapor argumentos orientados para conclusões contrárias. Pudemos verificar que o editorialista baseia-se, principalmente, no argumento por compatibilidade/incompatibilidade, com a finalidade de considerar opostos para "trazer o leitor para si" e tornar-se mais persuasivo; no argumento pragmático, porque pode partir de uma postura de identidade com o auditório que possa contribuir para a persuasão; no argumento por ilustração que não depende de adesão à regra, mas deve impressionar a imaginação para imporse à atenção. Isso permite afirmar que há uma correlação entre os dois tipos de operadores argumentativos mais usados como estratégias básicas da argumentação, que vão somando e se opondo, e os tipos de argumento mais frequentes.

Acreditamos que nosso trabalho tenha atingido os objetivos propostos e tenha contribuído para os estudos linguísticos, porque permitiu verificar a importância do uso dos operadores argumentativos nos editoriais e a relação que têm com as técnicas argumentativas. Isso nos autoriza a ressaltar a necessidade de chamar a atenção dos usuários da Língua Portuguesa para o valor argumentativo dos operadores (daí sua importância para o ensino), e 
afirmar que parte da força argumentativa dos enunciados encontra-se na dependência deles, independentemente de quais sejam usados.

\section{Referências}

AGUSTINI, Carmen Lúcia Hernandes. Um estudo do uso de operadores argumentativos no gênero editorial de jornal. 2006. 223 f. Dissertação (Mestrado em Linguística) - Universidade Federal de Uberlândia, Uberlândia.

DUCROT, Oswald. Provar e dizer: linguagem e lógica. Tradução de Maria Aparecida Barbosa, Maria de Fátima G. Moreira e Cidmar Teodoro País. São Paulo: Global Ed., 1981.

. Argumentação e topoi argumentativos. In: DUCROT, Oswald. História e sentido na linguagem. Campinas: Cortez, 1989.

ERBOLATO, Mário Lauro. Jornalismo especializado: emissão de textos no jornalismo impresso. São Paulo: Atlas, 1981.

GUIMARÃES, Eduardo. Os limites do sentido: um estudo histórico e enunciativo da linguagem. Campinas: Pontes, 1995.

KOCH, Ingedore Villaça . Argumentação e linguagem. São Paulo: Cortez, 1984.

. Introdução à Linguística Textual. São Paulo: Martins Fontes, 2004. (Coleção Texto e Linguagem).

LOPES, Valdir Luiz. A formação do professor de língua portuguesa e alguns aspectos retóricos de seu discurso. 2005. Tese (Doutorado em Educação) Faculdade de Educação da Universidade de São Paulo, São Paulo, 2005.

PERELMAN, Chaïm; OLBRECHTS-TYTECA, Lucie. Tratado da argumentação: A nova retórica. Tradução de Maria Ermantina Galvão G. Pereira. São Paulo: Martins Fontes, 1999.

REBOUL, Olivier. Introdução à Retórica. Tradução Ivone Castilho Benedetti. São Paulo: Martins Fontes, 1998.

TRAVAGLIA, Luiz Carlos. Gramática e interação: uma proposta para o ensino da gramática no $1^{\circ}$ e $2^{\circ}$ graus. São Paulo: Cortez, 1996. 